\title{
Genomic imprinting and its relevance to congenital disease, infertility, molar pregnancy and induced pluripotent stem cell
}

\author{
Shin-ichi Tomizawa ${ }^{1}$ and Hiroyuki Sasaki ${ }^{2}$ \\ Genomic imprinting is an epigenetic gene-marking phenomenon that occurs in the germline, whereby genes are expressed from \\ only one of the two parental copies in embryos and adults. Imprinting is essential for normal mammalian development and its \\ disruption can cause various developmental defects and diseases. The process of imprinting in the germline involves DNA \\ methylation of the imprint control regions (ICRs), and resulting parental-specific methylation imprints are maintained in the \\ zygote and act as the marks controlling imprinted gene expression. Recent studies in mice have revealed new factors involved in \\ imprint establishment during gametogenesis and maintenance during early development. Clinical studies have identified cases \\ of imprinting disorders where involvement of factors shared by multiple ICRs for establishment or maintenance is suspected. \\ These include Beckwith-Wiedemann syndrome, transient neonatal diabetes, Silver-Russell syndrome and others. More severe \\ disruptions can lead to recurrent molar pregnancy, miscarriage or infertility. Imprinting defects may also occur during assisted \\ reproductive technology or cell reprogramming. In this review, we summarize our current knowledge on the mechanisms of \\ imprint establishment and maintenance, and discuss the relationship with various human disorders.
}

Journal of Human Genetics (2012) 57, 84-91; doi:10.1038/jhg.2011.151; published online 12 January 2012

Keywords: DNA methylation; germ cells; imprinting; induced pluripotent stem cells; infertility; molar pregnancy; reproduction

\section{OVERVIEW OF GENOMIC IMPRINTING}

Unlike most autosomal genes, which are expressed biallelically, a certain number of genes in mammals show highly biased or even monoallelic expression dependent on parental origin. The unique expression patterns are brought about by differences in epigenetic marks between the parental copies, which are established in the parental germline. This germline-specific gene-marking phenomenon is called genomic imprinting. Imprinting was first discovered by embryological experiments in mice, which showed that normal development requires both a paternal and a maternal genome., ${ }^{1,2}$ Almost at the same time, geneticists found by making uniparental disomies that certain mouse chromosome regions have differential activity depending on their parental origin. ${ }^{3}$ These results clearly pointed to the existence of imprinting phenomenon in mammals, and the first imprinted gene Igf2r was identified in $1991 .^{4}$ The number of imprinted genes identified so far is around 100 in both humans and mice, but a recent study suggested that this may expand to over $1000 .{ }^{5}$

DNA methylation is a critical component of the imprinting mechanism, ${ }^{6}$ and allele-specific methylation is often found in imprinted gene regions (differentially methylated regions or DMRs). ${ }^{7}$ There are two DMR classes: primary DMRs and secondary DMRs. The primary or germline DMRs acquire methylation in the germline (Figure 1) and often identical with imprint control regions (ICRs). The ICRs regulate expression of one or more proximal genes (imprinted genes often form clusters) through complex mechanisms involving non-coding RNAs, histone modifications, insulators and a higher order chromatin structure $^{8}$ Many ICRs have been identified and characterized by targeted deletion in mice, which often results in dysregulation of the entire imprinted cluster. ${ }^{9-15}$ Such mouse models often show phenotypes reminiscent of human diseases, and are useful for understanding their molecular mechanisms, which we will discuss later. The secondary or somatic DMRs acquire methylation after fertilization under the control of nearby ICRs. ${ }^{7}$ Once established in either gametes, the methylation imprint at an ICR is passed to the zygote and stably maintained in somatic lineages throughout its life (Figure 1). ${ }^{16}$ However, the differential methylation is erased in primordial germ cells in each generation before the new imprints are set. ${ }^{17-19}$

\section{THE MECHANISM OF IMPRINT ESTABLISHMENT IN THE GERMLINE}

The first step of the imprinting cycle, imprint establishment, occurs in male and female gametogenesis. Imprint establishment takes place in

\footnotetext{
${ }^{1}$ Epigenetics Programme, The Babraham Institute, Cambridge, UK and 2Division of Epigenomics, Department of Molecular Genetics, Medical Institute of Bioregulation, and Epigenome Network Research Center, Kyushu University, Fukuoka, Japan

Correspondence: Professor H Sasaki, Division of Epigenomics, Department of Molecular Genetics, Medical Institute of Bioregulation, and Epigenome Network Research Center, Kyushu University, Fukuoka, Japan.

E-mail: hsasaki@bioreg.kyushu-u.ac.jp

Received 9 November 2011; revised 13 December 2011; accepted 14 December 2011; published online 12 January 2012
} 


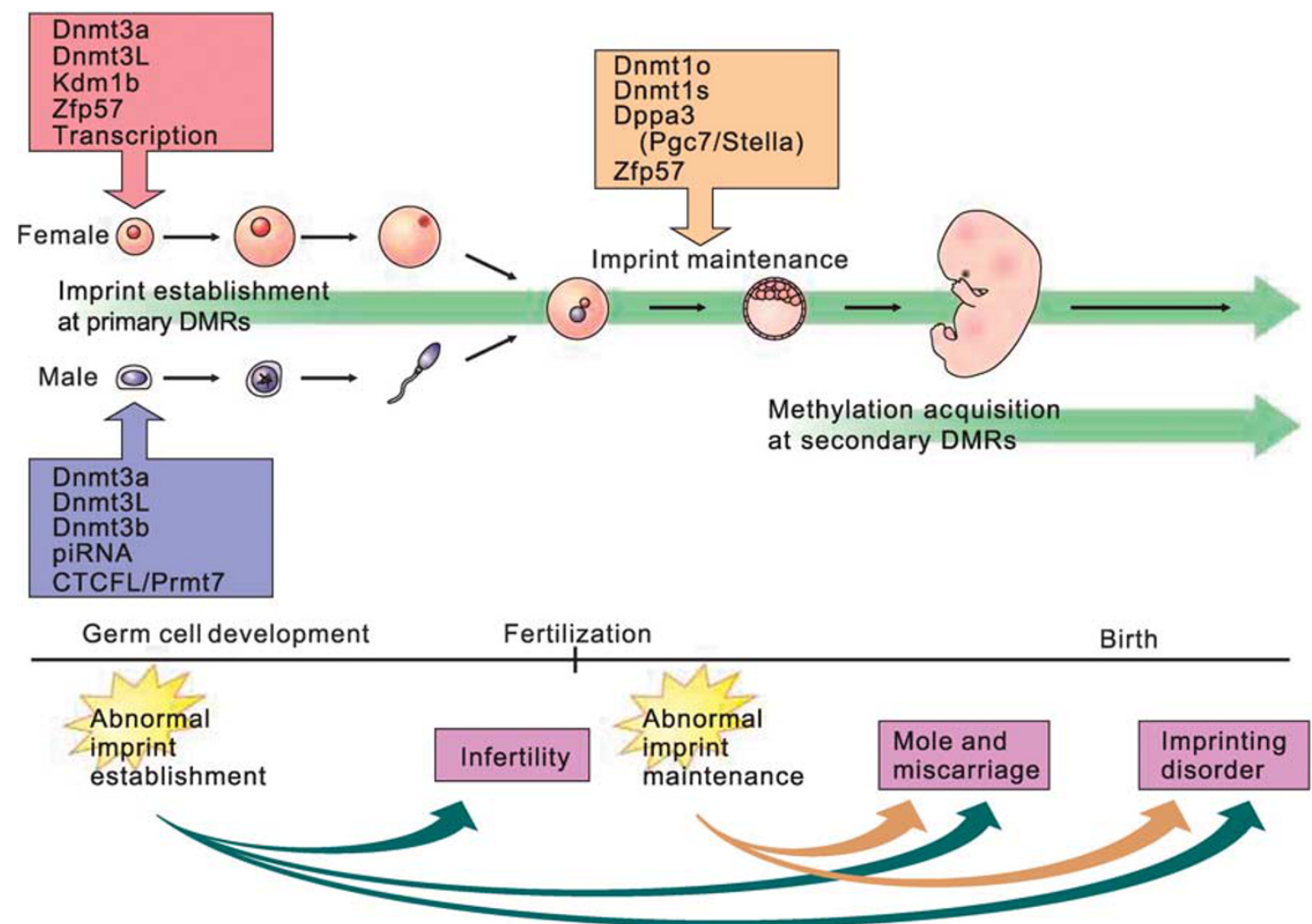

Figure 1 Chronology of genomic imprinting and various factors involved in the two major steps, establishment and maintenance. The steps affected in infertility, molar pregnancies and miscarriage, and imprinting disorders are also shown.

growing oocytes in females and prospermatogonia in males. Oocyte growth occurs in the postnatal ovary, and growing oocytes are in the diplotene stage of meiotic prophase I. Prospermatogonia are G1arrested male germ cells in the fetal testis, which eventually give rise to spermatogonia after birth. Below we summarize the recent advancement in studies on the mechanisms of imprint establishment in mice.

It has been shown by gene knockout experiments that the de novo DNA methyltransferase essential for imprint establishment is Dnmt3a in both male and female germlines (Figure 1). ${ }^{20-22}$ This enzyme forms a complex with the structurally related, germ-cell-specific cofactor Dnmt3L, which enhances the catalytic activity of Dnmt3a and is important for imprint establishment (Figure 1). ${ }^{21,23-25}$ The other de novo methyltransferase Dnmt $3 \mathrm{~b}$ is not involved, except at one particular ICR (see later). Thus, the key proteins in the imprint establishment machinery have been identified, but how they are recruited to specific targets is less clear.

Factors and features identified so far as specificity determinants for imprinting in oocytes include: (1) transcription traversing ICRs (Figure 1), ${ }^{26}$ (2) unmethylated lysine-4 of histone $\mathrm{H} 3$ (H3K4), ${ }^{27}$ (3) 10-bp CpG spacing, ${ }^{28}$ (4) a histone H3K4 demethylase Kdmlb (Figure 1$)^{29}$ and (5) a Krüppel-associated box (KRAB) zinc finger protein Zfp57 (Figure 1). ${ }^{30}$ Among these, the first three seem common to all oocyte-methylated ICRs and could be prerequisites for imprint establishment. Transcription through ICRs may make the chromatin more accessible by the Dnmt3a-Dnmt3L complex; ${ }^{26}$ unmethylated, but not methylated, $\mathrm{H} 3 \mathrm{~K} 4$ is the high-affinity binding target of Dnmt3L; $;{ }^{27}$ two CpG sites located 10-bp apart fit very well with the catalytic centers of the heterotetrameric Dnmt3a-Dnmt3L complex. ${ }^{28}$ However, these features can be found elsewhere in the genome and are not specific to ICRs. By contrast, Kdmlb acts only on a subset of ICRs (for example, ICRs at Mest, Grb10, Plagl1 and Impact loci), ${ }^{29}$ although demethylation of $\mathrm{H} 3 \mathrm{~K} 4$ by this enzyme is consistent with the preference of Dnmt3L for unmethylated H3K4. The involvement of Zfp57 appears to be more restricted, and so far the Snrpn ICR is its only known target in oocytes, although it is involved in imprint maintenance at multiple ICRs after fertilization (see later). ${ }^{30}$ Therefore, the process of specificity determination seems complicated, and perhaps combinations of common and ICR-specific factors may eventually produce the specificity. An alternative view is that there is no specific targeting of methylation to DMRs; instead, they represent a subset of CpG islands that acquire methylation in oocytes in response to general mechanisms of methylation. ${ }^{31}$

We recently found that methylation of the Rasgrf1 ICR in prospermatogonia involves the PIWI-interacting RNA machinery (Figure 1). ${ }^{32}$ Evidence suggests that recruitment of the Dnmt3a-Dnmt3L complex requires an interaction between the non-coding RNA traversing the ICR and PIWI-interacting RNAs complementary to this RNA. So far, this is the only ICR involving the PIWI-interacting RNA pathway, and it is interesting that the involvement of Dnmt3b is also unique to this ICR. ${ }^{21}$ At the H19 ICR, CTCFL (also known as BORIS) and a protein arginine methyltransferase Prmt7 appear to have roles in methylation imprint establishment in prospermatogonia (Figure 1). ${ }^{33}$ CTCFL is a paralog of the insulator protein CTCF and highly expressed in the male germline. Recently, it was found that imprinted loci retain histones in mature sperm, raising the possibility that histone modification can be an imprint. ${ }^{34}$ Notably, H3K4me3 is enriched at regions with no methylation in sperm, suggesting that this mark might protect the oocyte-methylated ICRs from methylation in the male germline. ${ }^{34,35}$ 


\section{IMPRINT MAINTENANCE IN EARLY EMBRYOS}

The methylation imprints established in the parental germline should be protected from the genome-wide reprogramming including global DNA demethylation during early embryogenesis. In preimplantation embryos, the methylation imprints at ICRs are first copied by the activity of the oocyte-stored form of the maintenance DNA methyltransferase Dnmtlo and then by zygotically expressed somatic form Dnmt1s (Figure 1). ${ }^{36}$ Interestingly, a recent study identified over a thousand CpG islands methylated by the Dnmt3a-Dnmt3L complex in oocytes. ${ }^{37}$ Most of them are thought not to relate to imprinting and lose methylation at least partially during preimplantation development. This indicates the existence of mechanisms that recruit protection factors and/or maintenance enzymes specifically to ICRs. Dppa3 (also known as Pgc7 or Stella) is one protein that protects the maternal imprints from demethylation (Figure 1). ${ }^{38}$ It likely acts through protection against hydroxylation of 5-methylcytosine by the Tet3 protein. ${ }^{39}$ 5-hydroxymethylcytosine is not recognized by Dnmt1 and thus, without this protection, maternal imprints can be subject to replication-dependent passive demethylation. Zfp57 is an oocytederived maternal factor involved in preimplantation maintenance of both paternal and maternal imprints at multiple loci such as the paternally methylated intergenic ICR (IG-DMR) within the Dlk1Meg3 locus ( $\mathrm{Meg} 3$ is also known as Gtl2) and the maternally methylated Mest, Peg3 and Snrpn ICRs (Figure 1). ${ }^{30}$ However, there are ICRs that are not affected in $Z f p 57$ mutants (for example, $H 19$ and Igf2r ICRs). ${ }^{30}$ The mechanistic detail of this locus-specific protection is still lacking.

\section{CHILDHOOD DISEASES ASSOCIATED WITH IMPRINT ESTABLISHMENT OR EARLY MAINTENANCE}

Imprinted genes have key roles in growth and development, and imprinting disorders are typically accompanied by growth-related symptoms. ${ }^{40}$ Causes of imprinting disorders range from chromosomal and genetic abnormalities to epigenetic abnormalities and one imprinting disorder can result from a variety of molecular mechanisms. Chromosomal and genetic causes include uniparental disomies, chromosomal deletion, duplication, translocation, inversion and point mutation, all of which change the dosage of normal imprinted gene product(s). Epigenetic abnormality is mostly aberrant hypermethylation/hypomethylation at ICRs. We here focus on defects in establishment or early maintenance of imprints.

Beckwith-Wiedemann syndrome (BWS) is an overgrowth disorder characterized by macrosomia, macroglossia, organomegaly, omphalocele, neonatal hypoglycemia, ear creases or ear pits, and predisposition to childhood tumor. The chromosome region responsible for BWS is $11 \mathrm{p} 15.5$, which contains a large cluster of imprinted genes regulated by two ICRs: the KCNQ1OT1 ICR (or KvDMR1) is located in the 5 ' region of KCNQ1OT1 and maternally methylated, and the H19 ICR is located between $H 19$ and IGF2 and is paternally methylated (Figure 2). ${ }^{41}$ A variety of genetic defects have been identified in BWS patients, such as paternal uniparental disomies, deletion, duplication, translocation and mutations in CDKN1C. However, hypomethylation of the KCNQ1OT1 ICR is the most frequent $(50 \%)$ epigenetic change in BWS, and hypermethylation of the H19 ICR is another (5\%) (Table 1). ${ }^{41}$ Notably, it was reported that $20-24 \%$ of BWS cases are hypomethylated at multiple maternally imprinted loci other than the KCNQ1OT1 ICR (Table 1). ${ }^{42-44}$ Moreover, a homozygous mutation in a nucleotide-binding oligomerization domain, leucine rich repeat and pyrin domain-containing (NLRP) family gene, NLRP2 was found in a mother of two BWS children with the KCNQ1OT1 ICR hypomethylation, and one of the patients showed a loss of methylation at another maternally methylated MEST ICR. ${ }^{45}$ This implies a role for NLRP2 in the establishment and/or maintenance of methylation imprints at multiple ICRs.

Silver-Russell syndrome shows prenatal and postnatal growth retardation with heterogeneous clinical manifestations that are basically opposite to what is observed in BWS. A number of chromosomes and potential candidate genes are suggested to be associated with the disease, but a large proportion of Silver-Russell syndrome is linked to the same genomic region as BWS (11p15.5) and maternal uniparental disomies is one major cause (Figure 2). ${ }^{46}$ Epigenetic abnormalities are detected in up to $35-65 \%$ of patients, the most frequent one being hypomethylation of the H19 ICR (Table 1). ${ }^{46-52}$ Like BWS cases, a proportion of patients with Silver-Russell syndrome show hypomethylation at multiple ICRs (Table 1). ${ }^{43,53}$ Moreover, over two-third of such patients have hypomethylation not only at the maternally methylated ICRs but also at another paternally methylated ICR at the DLK1MEG3 locus (IG-DMR) (Table 1). ${ }^{43}$ This suggests that the primary defect probably affects post-fertilization maintenance. However, the causative gene responsible for this phenotype has not been identified.

Transient neonatal diabetes mellitus type 1 is a rare type of diabetes with hyperglycemia manifested within the first 6 months of life. This is caused by overexpression of the imprinted genes PLAGL1 and HYMAI in chromosome region $6 \mathrm{q} 24$. About $20 \%$ of patients with transient neonatal diabetes mellitus type 1 show loss of methylation at the PLAGL1/HYMAI ICR, which is normally maternally methylated (Figure 2 and Table 1). ${ }^{54,55}$ Over $50 \%$ of these patients also show hypomethylation at other maternally methylated ICRs across the genome, which was recently found to be associated with ZFP57 mutations (Table 1). ${ }^{54}$ The phenotype can be explained by defects in either establishment or maintenance of methylation imprints but, as noted above, studies on Zfp57 knock-out mice showed that its predominant role is in maintenance after fertilization. ${ }^{30}$ However, it is important to note that some individuals with hypomethylation at multiple ICRs carry no mutation in ZFP57, indicating the existence of other factors.

Pseudohypoparathyroidism type Ib, an endocrine disorder characterized by renal resistance to parathyroid hormone, is associated with loss of methylation at a maternally methylated ICR located at GNAS exon A/B in chromosome region 20q13.3 (Figure 2 and Table 1). ${ }^{56-59}$ A remarkable finding with this disorder is that genetic mutations underlying the loss of methylation were initially mapped $\geqslant 56 \mathrm{~kb}$ upstream of the exon A/B ICR, indicating the presence of a longrange, cis-acting element. ${ }^{56}$ Furthermore, heterozygous microdeletions at STX16, located approximately $220 \mathrm{~kb}$ upstream of the GNAS exon A/B ICR, were also found in most cases of autosomal dominant form of pseudohypoparathyroidism type $\mathrm{Ib}^{.57,60-62}$ STX16 appears to be a non-imprinted gene, but only maternal transmission of these microdeletions leads to this disorder, suggesting the existence of another long-range cis-acting element. Another study identified maternally transmitted deletions of an upstream exon of the NESP55 transcript within the GNAS locus in two families, which were associated with methylation defects at all downstream GNAS ICRs located at exons AS1, XL and A/B (Figure 2 and Table 1). ${ }^{63}$ At least some of these deletions could affect transcription of NESP55 in oocytes, which is presumed to proceed through AS1, XL and exon A/B. In light of the study on the mouse Gnas locus, ${ }^{26}$ it is conceivable that the absence of NESP55 transcription leads to a failure in imprint establishment.

Angelman syndrome (AS) is a neurodevelopmental disorder caused by a deficiency of a maternally expressed imprinted gene $U B E 3 A .^{64,65}$ AS is usually associated with genetic abnormalities at an imprinted cluster containing UBE3A within 15q11-q13, and approximately $2-4 \%$ of the patients show epigenetic defects at this region, which 


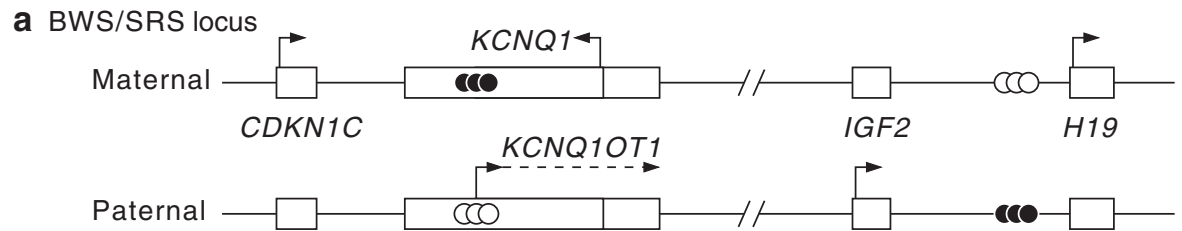

b TNDM1 locus
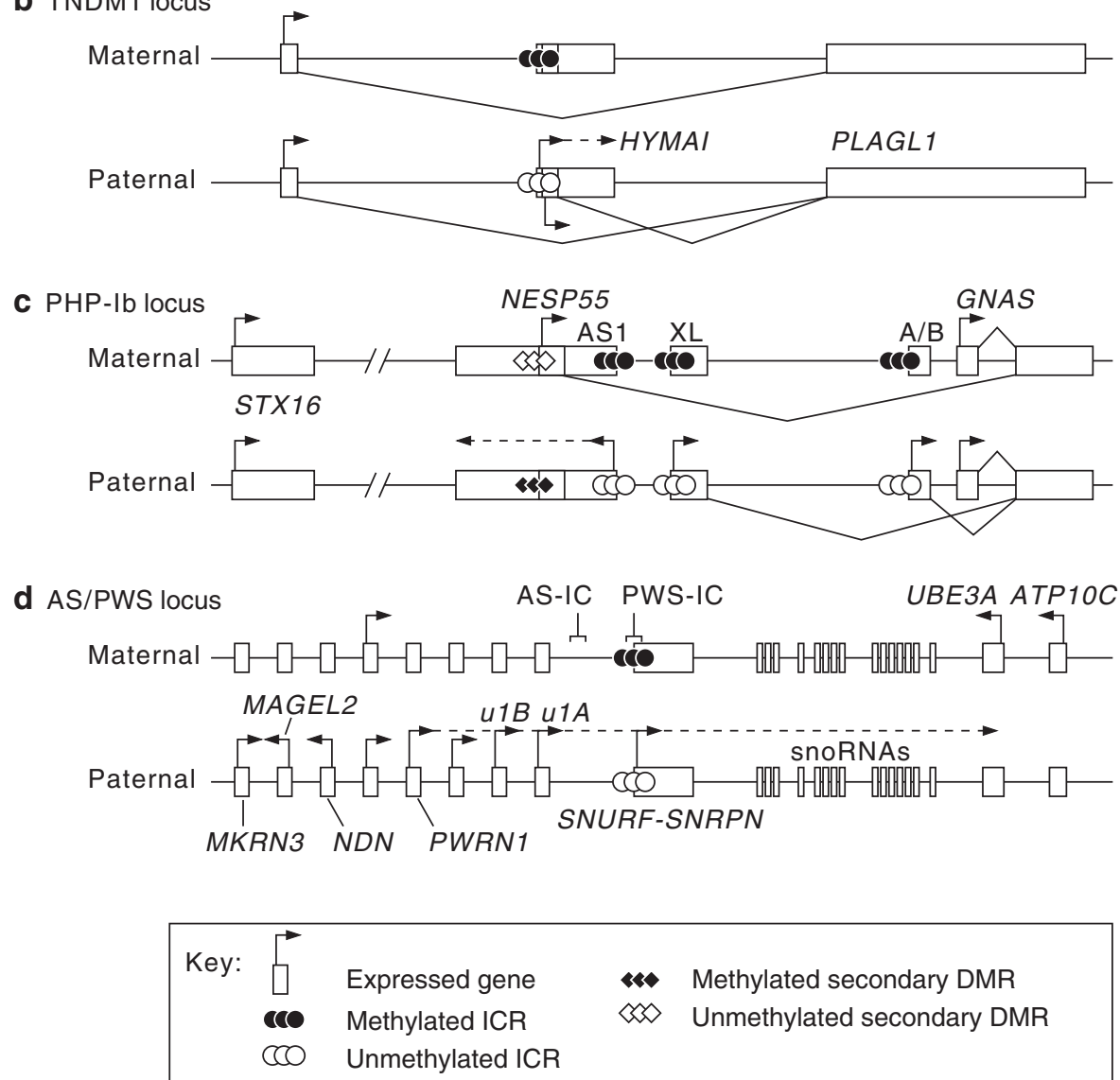

Figure 2 Schematic representation of the human-imprinted loci associated with diseases (not drawn to scale). (a) The KCNQ1 and H19 loci for BeckwithWiedemann syndrome (BWS) and Silver-Russell syndrome (SRS) in $11 \mathrm{p} 15.5$. (b) The PLAGL1/HYMAl locus for transient neonatal diabetes mellitus type 1 (TNDM1) in 6q24. PLAGL1 has an upstream promoter, which is biallelically expressed. The ICR overlaps with a promoter shared by PLAGL1 and HYMAI. (c) The GNAS locus and STX16 for pseudohypoparathyroidism type Ib (PHP-lb) in 20q13.3. (d) The SNRPN locus for Angelman syndrome (AS) and Prader-Willi syndrome (PWS) in 15q11-q13.

include loss of methylation at the ICR at an imprinted bicistronic transcript encoding small nuclear ribonucleoprotein $\mathrm{N}(S N R P N)$ and SNRPN upstream reading frame (SNURF) (referred to as SNRPN) (Figure 2 and Table 1). ${ }^{66-68}$ Among those, 92\% are thought to have epigenetic mutations occurring in either oocytes or early embryos. ${ }^{66}$ Maternally transmitted deletions of a region located $35 \mathrm{~kb}$ upstream of the SNRPN ICR, along with loss of methylation, have been identified in AS patients, which led to the discovery of the AS-imprinting center. ${ }^{69,70}$ The $S N R P N$ gene has a number of alternative transcripts, and AS-imprinting center overlaps with exons of such transcripts. ${ }^{71,72}$ Therefore, one possible explanation for some cases would be that the deletions affect oocyte-specific alternative transcripts traversing the SNRPN ICR, and this results in a failure in imprint establishment. Prader-Willi syndrome (PWS) is another neurogenetic disorder that results from the abnormalities of the same imprinted cluster as AS. In contrast to AS, chromosomal deletions found in PWS are always on the paternal chromosome. A de novo interstitial deletion affecting the entire imprinted domain, and a maternal uniparental disomy are the major causes of PWS ( $\sim 70 \%$ and $\sim 25-30 \%$, respectively), and about $1-3 \%$ of PWS is caused by abnormal imprinting. ${ }^{40,66}$ A small proportion of PWS patients with an imprinting defect carry a deletion at the PWS-imprinting center that lies at the promoter/exon 1 of SNRPN (Figure 2). ${ }^{66}$ However, most imprinting defects represent primary epimutations derived from the paternal grandmother. This suggests that, unlike other diseases, incorrect erasure of the imprint in the paternal primordial germ cells might have resulted in inheritance of a chromosome carrying an imprinting defect in such patients, ${ }^{66}$ but the factor involved in such defects is not clear.

\section{MOLAR PREGNANCY, INFERTILITY, ASSISTED REPRODUCTIVE TECHNOLOGY (ART) AND INDUCED PLURIPOTENT STEM (IPS)} CELLS

More severe defects in imprint establishment in the germline are probably incompatible with life and lead to infertility or miscarriage. 
Table 1 Methylation defects at ICRs reported in imprinting disease, molar pregnancy, infertility and iPS cells

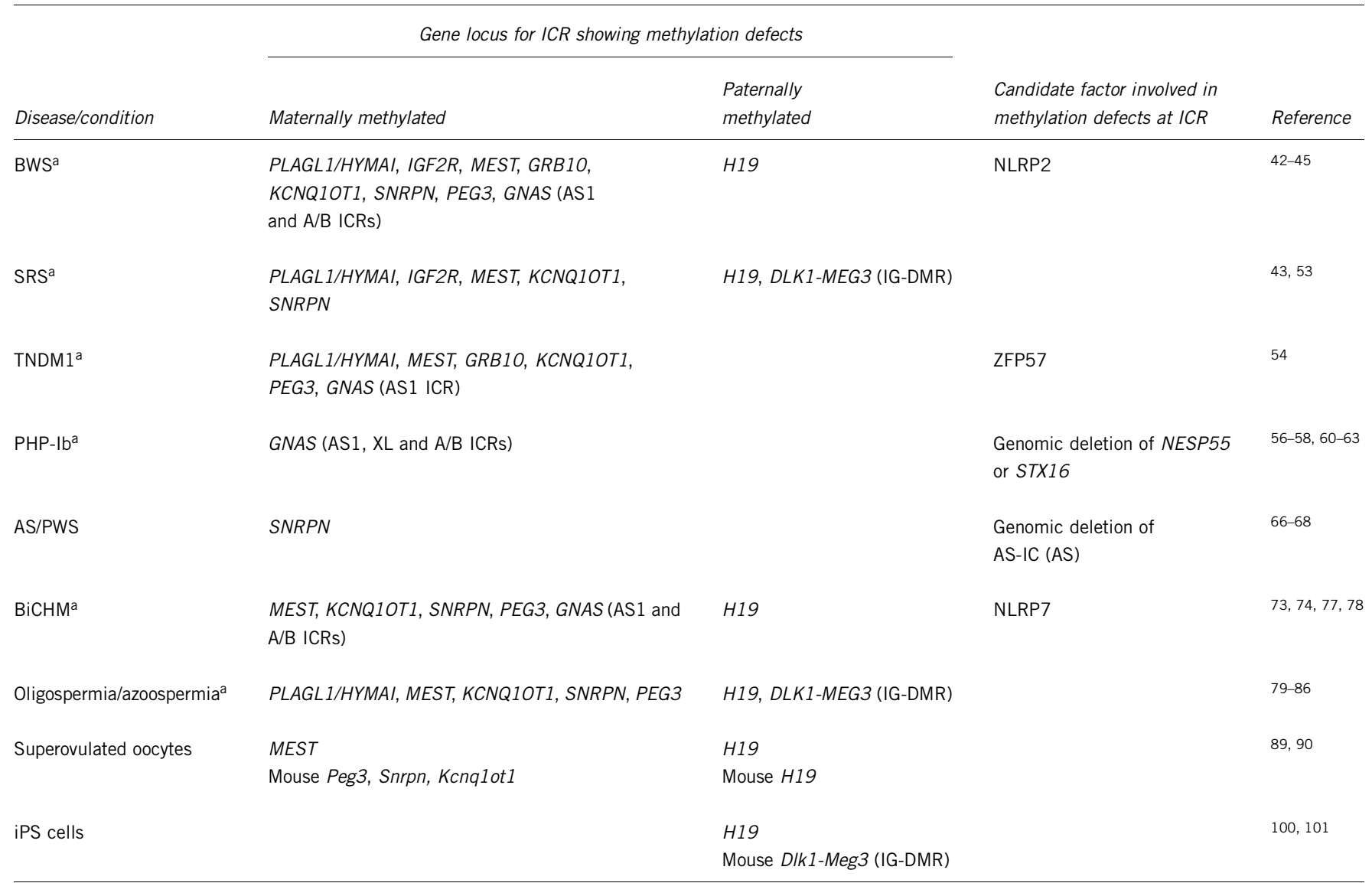

Abbreviations: AS, Angelman syndrome; BiCHM, biparental complete hydatidiform mole; BWS, Beckwith-Wiedemann syndrome; ICR, imprint control regions; iPS, induced pluripotent stem cells; PHP-Ib, pseudohypoparathyroidism type Ib; PWS, Prader-Willi syndrome; SRS, Silver-Russell syndrome; TNDM1, transient neonatal diabetes mellitus type 1.

alCRs involved may differ between cases and for many loss of methylation is partial.

Mutations in NLRP7, which is homologous to NLRP2, are found in familial recurrent biparental complete hydatidiform mole. ${ }^{73-75}$ A complete hydatidiform mole is usually the product of dipoid androgenesis, which results from fertilization of an 'empty' egg with subsequent diploidization of the paternal genome, and characterized by hyperproliferative vesicular trophoblast and no fetal development. ${ }^{76}$ Women with biparental complete hydatidiform mole have recurrent complete hydatidiform moles with normal diploid karyotype (one paternal and one maternal genome) but with loss of methylation imprints at multiple ICRs (Table 1). ${ }^{74,77,78}$ NLRP7 protein is possibly required for both establishment and maintenance of methylation imprints at multiple maternally methylated ICRs. ${ }^{74}$ Interestingly, NLRP7 is found only in a few species of mammals (human, primate and cow) and there is no strict homo$\log$ in rodents, although there are families of related proteins in all mammals.

In sperm from infertile patients with deficiencies such as oligospermia or azoospermia, aberrant methylation imprints at ICRs have been reported (Table 1). ${ }^{79-86}$ Abnormal methylation was observed in not only paternally methylated ICRs but also maternally methylated ICRs. At present, it is unclear how defects in methylation imprints are brought about in these patients, but one explanation could be aminoacid sequence variations in DNMT3L. ${ }^{87} \mathrm{~A}$ rare case of DNMT3L polymorphism was found to be associated with subtelomeric hypomethylation, ${ }^{88}$ but the relevance of such polymorphisms to abnormal
ICR methylation in oligospermic or azoospermic patients remains uncertain.

Although further large studies are needed to establish how common methylation defects are in oligospermic or azoospermic patients, the use of such sperm for ART may increase the risk of imprinting disorders in ART babies. Other reports suggest that proper acquisition of methylation can be perturbed by superovulation; loss of methylation was detected in oocytes at several maternally methylated ICRs (human MEST, mouse Peg3, Snrpn and Kcnq1ot1 ICRs) and gain of methylation was detected at a paternally methylated ICR (human and mouse H19 ICRs) (Table 1). ${ }^{89,90}$ A number of studies report that BWS and AS cases are overrepresented in children born through ART. ${ }^{42,91-95}$ However, other studies did not find evidence for increased risk for these diseases, ${ }^{96,97}$ and the relationship between ART and imprinting disorders remains to be established. ${ }^{98,99}$

Recently, it was reported that the expression state of the imprinted Dlk1-Dio3 cluster on mouse chromosome 12 is often altered in iPS cells. ${ }^{100}$ In the affected mouse iPS cell clones, the ICR within the cluster was abnormally methylated and associated imprinted genes, such as Meg3, were abnormally silenced (Table 1). Thus, the unmethylated state of the maternally derived ICR was not maintained during reprogramming. Furthermore, these iPS cell clones contributed poorly to chimeras and failed to support the development of entirely iPS cellderived mice, whereas embryos derived from iPS cell clones with normal Meg3 expression developed well. ${ }^{100}$ Clone- and gene-specific 
aberrations of imprinting were also reported in human iPS cells. ${ }^{101}$ These studies underscore the importance of the imprint maintenance mechanism in cell reprogramming.

\section{CONCLUSIONS}

In this review, we have summarized the current knowledge on the mechanisms of imprint establishment and maintenance and on the human disorders that may have resulted from defects in such mechanisms. Molecular studies in mice have highlighted the importance not only of DNA methylation but also other epigenetic marks and factors, and therefore future studies on human cases should include histone modifications and other factors. Recent technological advances in genome-wide epigenetic analysis will greatly enhance such studies. We also note that the precise mechanism of imprint establishment may differ between ICRs and, furthermore, there are species differences in factors involved: for example, NLRP7 has not been found in mice, and DNMT3L has not been detected in human oocytes. ${ }^{102,103}$ These findings reveal some limitations of mouse studies, despite the great advances made in this tractable model, and underscore the need for additional model systems appropriate for human studies. In this regard, the use of primate species or refinement of the recently developed in vitro germcell production system ${ }^{104}$ will be important for future studies.

\section{ACKNOWLEDGEMENTS}

We thank Dr Gavin Kelsey (The Babraham Institute) for critical reading of the manuscript. ST is supported by the UK Medical Research Council. This work was partially supported by a Grant-in-Aid for Scientific Research on Priority Area from the Ministry of Education, Culture, Sports, Science, and Technology of Japan to HS

1 McGrath, J. \& Solter, D. Completion of mouse embryogenesis requires both the maternal and paternal genomes. Cell. 37, 179-183 (1984).

2 Surani, M. A., Barton, S. C. \& Norris, M. L. Development of reconstituted mouse eggs suggests imprinting of the genome during gametogenesis. Nature. 308, 548-550 (1984)

3 Cattanach, B. M. \& Kirk, M. Differential activity of maternally and paternally derived chromosome regions in mice. Nature. 315, 496-498 (1985).

4 Barlow, D. P., Stoger, R., Herrmann, B. G., Saito, K. \& Schweifer, N. The mouse insulin-like growth factor type-2 receptor is imprinted and closely linked to the Tme locus. Nature. 349, 84-87 (1991).

5 Gregg, C., Zhang, J., Butler, J. E., Haig, D. \& Dulac, C. Sex-specific parent-of-origin allelic expression in the mouse brain. Science 329, 682-685 (2010).

$6 \mathrm{Li}, \mathrm{E} ., \mathrm{Beard}, \mathrm{C}$. \& Jaenisch, R. Role for DNA methylation in genomic imprinting. Nature. 366, 362-365 (1993).

7 Ferguson-Smith, A. C. Genomic imprinting: the emergence of an epigenetic paradigm. Nat Rev Genet. 12, 565-575 (2011).

8 Bartolomei, M. S. Genomic imprinting: employing and avoiding epigenetic processes. Genes Dev. 23, 2124-2133 (2009).

9 Thorvaldsen, J. L., Duran, K. L. \& Bartolomei, M. S. Deletion of the H19 differentially methylated domain results in loss of imprinted expression of H19 and Igf2. Genes Dev. 12, 3693-3702 (1998).

10 Fitzpatrick, G. V., Soloway, P. D. \& Higgins, M. J. Regional loss of imprinting and growth deficiency in mice with a targeted deletion of KvDMR1. Nat Genet. 32, 426-431 (2002).

11 Yoon, B. J., Herman, H., Sikora, A., Smith, L. T., Plass, C. \& Soloway, P. D. Regulation of DNA methylation of Rasgrf1. Nat Genet. 30, 92-96 (2002)

12 Lin, S. P., Youngson, N., Takada, S., Seitz, H., Reik, W., Paulsen, M. et al. Asymmetric regulation of imprinting on the maternal and paternal chromosomes at the DIk1-GtI2 imprinted cluster on mouse chromosome 12. Nat Genet. 35, 97-102 (2003).

13 Williamson, C. M., Ball, S. T., Nottingham, W. T., Skinner, J. A., Plagge, A., Turner, M. $D$. et al. A cis-acting control region is required exclusively for the tissue-specific imprinting of Gnas. Nat Genet. 36, 894-899 (2004).

14 Williamson, C. M., Turner, M. D., Ball, S. T., Nottingham, W. T., Glenister, P., Fray, M. et al. Identification of an imprinting control region affecting the expression of all transcripts in the Gnas cluster. Nat Genet. 38, 350-355 (2006).

15 Shiura, H., Nakamura, K., Hikichi, T., Hino, T., Oda, K., Suzuki-Migishima, R. et al. Paternal deletion of Meg1/Grb10 DMR causes maternalization of the Meg1/Grb10 cluster in mouse proximal Chromosome 11 leading to severe pre- and postnatal growth retardation. Hum Mol Genet. 18, 1424-1438 (2009).
16 Reik, W. \& Walter, J. Genomic imprinting: parental influence on the genome. Nat. Rev. Genet. 2, 21-32 (2001)

17 Reik, W., Dean, W. \& Walter, J. Epigenetic reprogramming in mammalian development. Science. 293, 1089-1093 (2001)

18 Sasaki, H. \& Matsui, Y. Epigenetic events in mammalian germ-cell development: reprogramming and beyond. Nat. Rev. Genet. 9, 129-140 (2008).

$19 \mathrm{Li}$, Y. \& Sasaki, H. Genomic imprinting in mammals: its life cycle, molecular mechanisms and reprogramming. Cell Res. 21, 466-473 (2011).

20 Kaneda, M., Hirasawa, R., Chiba, H., Okano, M., Li, E. \& Sasaki, H. Genetic evidence for Dnmt3a-dependent imprinting during oocyte growth obtained by conditional knockout with Zp3-Cre and complete exclusion of Dnmt3b by chimera formation. Genes Cells 15, 169-179 (2010).

21 Kato, Y., Kaneda, M., Hata, K. Kumaki, K., Hisano, M., Kohara, Y et al. Role of the Dnmt3 family in de novo methylation of imprinted and repetitive sequences during male germ cell development in the mouse. Hum Mol Genet. 16, 2272-2280 (2007).

22 Kaneda, M., Okano, M., Hata, K., Sado, T., Tsujimoto, N., Li, E. et al. Essential role for de novo DNA methyltransferase Dnmt3a in paternal and maternal imprinting. Nature. 429, 900-903 (2004).

23 Arnaud, P., Hata, K., Kaneda, M., Li, E., Sasaki, H., Feil, R. et al. Stochastic imprinting in the progeny of Dnmt3L-/- females. Hum Mol Genet. 15, 589-598 (2006).

24 Bourc'his, D., Xu, G. L., Lin, C. S., Bollman, B. \& Bestor, T. H. Dnmt3L and the establishment of maternal genomic imprints. Science. 294, 2536-2539 (2001).

25 Hata, K., Okano, M., Lei, H. \& Li, E. Dnmt3L cooperates with the Dnmt3 family of de novo DNA methyltransferases to establish maternal imprints in mice. Development. 129, 1983-1993 (2002).

26 Chotalia, M., Smallwood, S. A., Ruf, N., Dawson, C., Lucifero, D., Frontera, M. et al. Transcription is required for establishment of germline methylation marks at imprinted genes. Genes Dev. 23, 105-117 (2009).

27 Ooi, S. K., Qiu, C., Bernstein, E., Li, K., Jia, D., Yang, Z. et al. DNMT3L connects unmethylated lysine 4 of histone $\mathrm{H} 3$ to de novo methylation of DNA. Nature. 448, 714-717 (2007).

28 Jia, D., Jurkowska, R. Z., Zhang, X., Jeltsch, A. \& Cheng, X. Structure of Dnmt3a bound to Dnmt3L suggests a model for de novo DNA methylation. Nature. 449, 248 251 (2007).

29 Ciccone, D. N., Su, H., Hevi, S., Gay, F., Lei, H., Bajko, J. et al. KDM1B is a histone H3K4 demethylase required to establish maternal genomic imprints. Nature. 461, 415-418 (2009)

30 Li, X., Ito, M., Zhou, F., Youngson, N., Zuo, X., Leder, P. et al. A maternal-zygotic effect gene, Zfp57, maintains both maternal and paternal imprints. Dev Cell. 15, 547-557 (2008).

31 Smallwood, S. A. \& Kelsey, G. De novo DNA methylation: a germ cell perspective. Trends Genet. 28, 33-42 (2012).

32 Watanabe, T., Tomizawa, S., Mitsuya, K., Totoki, Y., Yamamoto, Y., KuramochiMiyagawa, S. et al. Role for piRNAs and noncoding RNA in de novo DNA methylation of the imprinted mouse Rasgrf1 locus. Science. 332, 848-852 (2011).

33 Jelinic, P., Stehle, J. C. \& Shaw, P. The testis-specific factor CTCFL cooperates with the protein methyltransferase PRMT7 in $\mathrm{H} 19$ imprinting control region methylation. PLOS Biol. 4, e355 (2006).

34 Hammoud, S. S., Nix, D. A., Zhang, H., Purwar, J., Carrell, D. T. \& Cairns, B. R. Distinctive chromatin in human sperm packages genes for embryo development. Nature. 460, 473-478 (2009).

35 Delaval, K., Govin, J., Cerqueira, F., Rousseaux, S., Khochbin, S. \& Feil, R. Differential histone modifications mark mouse imprinting control regions during spermatogenesis. EMBO J. 26, 720-729 (2007)

36 Hirasawa, R., Chiba, H., Kaneda, M., Tajima, S., Li, E., Jaenisch, R. et al. Maternal and zygotic Dnmt1 are necessary and sufficient for the maintenance of DNA methylation imprints during preimplantation development. Genes Dev. 22, 16071616 (2008).

37 Smallwood, S. A., Tomizawa, S. Krueger, F., Ruf, N., Carli, N., Segonds-Pichon, A. et al. Dynamic CpG island methylation landscape in oocytes and preimplantation embryos. Nat Genet. 43, 811-814 (2011).

38 Nakamura, T., Arai, Y., Umehara, H., Masuhara, M., Kimura, T., Taniguchi, H. et al. PGC7/Stella protects against DNA demethylation in early embryogenesis. Nat Cell Biol. 9, 64-71 (2007).

39 Wossidlo, M., Nakamura, T., Lepikhov, K., Marques, C. J., Zakhartchenko, V., Boiani, M. et al. 5-Hydroxymethylcytosine in the mammalian zygote is linked with epigenetic reprogramming. Nat. Comm. 2, 241 (2011).

40 Butler, M. G. Genomic imprinting disorders in humans: a mini-review. J. Assist. Reprod. Genet. 26, 477-486 (2009).

41 Weksberg, R., Shuman, C. \& Beckwith, J. B. Beckwith-Wiedemann syndrome. Eur. J. Hum. Genet. 18, 8-14 (2010).

42 Rossignol, S., Steunou, V., Chalas, C., Kerjean, A., Rigolet, M., Viegas-Pequignot, E. et al. The epigenetic imprinting defect of patients with Beckwith-Wiedemann syndrome born after assisted reproductive technology is not restricted to the $11 \mathrm{p} 15$ region. J. Med. Genet. 43, 902-907 (2006).

43 Azzi, S., Rossignol, S., Steunou, V., Sas, T., Thibaud, N., Danton, F. et al. Multilocus methylation analysis in a large cohort of $11 \mathrm{p} 15$-related foetal growth disorders (Russell Silver and Beckwith Wiedemann syndromes) reveals simultaneous loss of methylation at paternal and maternal imprinted loci. Hum Mol Genet. 18, 4724-4733 (2009).

44 Bliek, J., Verde, G., Callaway, J., Maas, S. M., De Crescenzo, A., Sparago, A. et al. Hypomethylation at multiple maternally methylated imprinted regions including 
PLAGL1 and GNAS loci in Beckwith-Wiedemann syndrome. Eur. J. Hum. Genet. : EJHG. 17, 611-619 (2009).

45 Meyer, E., Lim, D., Pasha, S., Tee, L. J., Rahman, F., Yates, J. R. et al. Germline mutation in NLRP2 (NALP2) in a familial imprinting disorder (Beckwith-Wiedemann Syndrome). PLoS Genet. 5, e1000423 (2009).

46 Abu-Amero, S., Wakeling, E. L., Preece, M., Whittaker, J., Stanier, P. \& Moore, G. E. Epigenetic signatures of Silver-Russell syndrome. J. Med. Genet. 47, 150-154 (2010).

47 Binder, G., Seidel, A. K., Martin, D. D., Schweizer, R., Schwarze, C. P., Wollmann, H. A. et al. The endocrine phenotype in silver-russell syndrome is defined by the underlying epigenetic alteration. J. Clin. Endocrinol. Metab. 93, 1402-1407 (2008).

48 Bliek, J., Terhal, P., van den Bogaard, M. J., Maas, S., Hamel, B., Salieb-Beugelaar, G. et al. Hypomethylation of the H19 gene causes not only Silver-Russell syndrome (SRS) but also isolated asymmetry or an SRS-like phenotype. Am J Hum Genet. 78, 604-614 (2006).

49 Eggermann, T., Schonherr, N., Meyer, E., Obermann, C., Mavany, M., Eggermann, K. et al. Epigenetic mutations in $11 \mathrm{p} 15$ in Silver-Russell syndrome are restricted to the telomeric imprinting domain. J. Med. Genet. 43, 615-616 (2006).

50 Gicquel, C., Rossignol, S., Cabrol, S., Houang, M., Steunou, V., Barbu, V. et al. Epimutation of the telomeric imprinting center region on chromosome $11 \mathrm{p} 15$ in Silver-Russell syndrome. Nat Genet. 37, 1003-1007 (2005).

51 Netchine, I., Rossignol, S., Dufourg, M. N., Azzi, S., Rousseau, A., Perin, L. et al. 11 p15 imprinting center region 1 loss of methylation is a common and specific cause of typical Russell-Silver syndrome: clinical scoring system and epigenetic-phenotypic correlations. J. Clin. Endocrinol. Metab. 92, 3148-3154 (2007).

52 Yamazawa, K., Kagami, M., Nagai, T., Kondoh, T., Onigata, K., Maeyama, K. et al. Molecular and clinical findings and their correlations in Silver-Russell syndrome: implications for a positive role of IGF2 in growth determination and differential imprinting regulation of the IGF2-H19 domain in bodies and placentas. $J \mathrm{Mol}$ Med (Berl). 86, 1171-1181 (2008).

53 Horike, S., Ferreira, J. C., Meguro-Horike, M., Choufani, S., Smith, A. C., Shuman, C. et al. Screening of DNA methylation at the $\mathrm{H} 19$ promoter or the distal region of its ICR 1 ensures efficient detection of chromosome 11 p15 epimutations in RussellSilver syndrome. Am. J. Med. Genet. Part A. 149A, 2415-2423 (2009).

54 Mackay, D. J., Callaway, J. L., Marks, S. M., White, H. E., Acerini, C. L., Boonen, S. E. et al. Hypomethylation of multiple imprinted loci in individuals with transient neonatal diabetes is associated with mutations in ZFP57. Nat Genet. 40, 949-951 (2008).

55 Mackay, D. J. \& Temple, I. K. Transient neonatal diabetes mellitus type 1. Am. J. Med. Genet. Part C, Seminars in medical genetics. 154C, 335-342 (2010).

56 Bastepe, M., Pincus, J. E., Sugimoto, T., Tojo, K., Kanatani, M., Azuma, Y. et al. Positional dissociation between the genetic mutation responsible for pseudohypoparathyroidism type $\mathrm{Ib}$ and the associated methylation defect at exon $\mathrm{A} / \mathrm{B}$ : evidence for a long-range regulatory element within the imprinted GNAS1 locus. Hum. Mol. Genet. 10, 1231-1241 (2001).

57 Linglart, A., Bastepe, M. \& Juppner, H. Similar clinical and laboratory findings in patients with symptomatic autosomal dominant and sporadic pseudohypoparathyroidism type Ib despite different epigenetic changes at the GNAS locus. Clin. Endocrinol. (Oxf). 67, 822-831 (2007).

58 Liu, J., Litman, D., Rosenberg, M. J., Yu, S., Biesecker, L. G. \& Weinstein, L. S. A GNAS1 imprinting defect in pseudohypoparathyroidism type IB. J. Clin. Invest. 106, 1167-1174 (2000)

59 Plagge, A., Kelsey, G. \& Germain-Lee, E. L. Physiological functions of the imprinted Gnas locus and its protein variants Galpha(s) and XLalpha(s) in human and mouse. J. Endocrinol. 196, 193-214 (2008).

60 Mantovani, G., Bondioni, S., Linglart, A., Maghnie, M., Cisternino, M., Corbetta, S. et al. Genetic analysis and evaluation of resistance to thyrotropin and growth hormonereleasing hormone in pseudohypoparathyroidism type Ib. J. Clin. Endocrinol. Metab. 92, 3738-3742 (2007)

61 Bastepe, M., Frohlich, L. F., Hendy, G. N., Indridason, O. S., Josse, R. G., Koshiyama, $\mathrm{H}$. et al. Autosomal dominant pseudohypoparathyroidism type Ib is associated with a heterozygous microdeletion that likely disrupts a putative imprinting control element of GNAS. J. Clin. Invest. 112, 1255-1263 (2003).

62 Linglart, A., Gensure, R. C., Olney, R. C., Juppner, H. \& Bastepe, M. A novel STX16 deletion in autosomal dominant pseudohypoparathyroidism type Ib redefines the boundaries of a cis-acting imprinting control element of GNAS. Am. J. Hum. Genet. 76, 804-814 (2005)

63 Bastepe, M., Frohlich, L. F., Linglart, A., Abu-Zahra, H. S., Tojo, K., Ward, L. M. et al. Deletion of the NESP55 differentially methylated region causes loss of maternal GNAS imprints and pseudohypoparathyroidism type Ib. Nat. Genet. 37, 25-27 (2005).

64 Kishino, T., Lalande, M. \& Wagstaff, J. UBE3A/E6-AP mutations cause Angelman syndrome. Nat Genet. 15, 70-73 (1997).

65 Matsuura, T., Sutcliffe, J. S., Fang, P., Galjaard, R. J., Jiang, Y. H., Benton, C. S. et al. De novo truncating mutations in E6-AP ubiquitin-protein ligase gene (UBE3A) in Angelman syndrome. Nat Genet. 15, 74-77 (1997).

66 Buiting, K. Prader-Willi syndrome and Angelman syndrome. Am. J. Med. Genet. Part C, Seminars in medical genetics 154C, 365-376 (2010).

67 Buiting, K., Dittrich, B., Gross, S., Lich, C., Farber, C., Buchholz, T. et al. Sporadic imprinting defects in Prader-Willi syndrome and Angelman syndrome: implications for imprint-switch models, genetic counseling, and prenatal diagnosis. Am J Hum Genet. 63, 170-180 (1998).

68 Buiting, K., Gross, S., Lich, C., Gillessen-Kaesbach, G., el-Maarri, O. \& Horsthemke, B. Epimutations in Prader-Willi and Angelman syndromes: a molecular study of 136 patients with an imprinting defect. Am J Hum Genet. 72, 571-577 (2003)
69 Buiting, K., Lich, C., Cottrell, S., Barnicoat, A. \& Horsthemke, B. A 5-kb imprinting center deletion in a family with Angelman syndrome reduces the shortest region of deletion overlap to 880 bp. Hum. Genet. 105, 665-666 (1999).

70 Horsthemke, B. \& Wagstaff, J. Mechanisms of imprinting of the Prader-Willi/Angelman region. Am. J. Med. Genet. Part A 146A, 2041-2052 (2008).

71 Dittrich, B., Buiting, K., Korn, B., Rickard, S., Buxton, J., Saitoh, S. et al. Imprint switching on human chromosome 15 may involve alternative transcripts of the SNRPN gene. Nat. Genet. 14, 163-170 (1996).

72 Farber, C., Dittrich, B., Buiting, K. \& Horsthemke, B. The chromosome 15 imprinting centre (IC) region has undergone multiple duplication events and contains an upstream exon of SNRPN that is deleted in all Angelman syndrome patients with an IC microdeletion. Hum. Mol. Genet. 8, 337-343 (1999).

73 Djuric, U., El-Maarri, O., Lamb, B., Kuick, R., Seoud, M., Coullin, P. et al. Familial molar tissues due to mutations in the inflammatory gene, NALP7, have normal postzygotic DNA methylation. Hum. Genet. 120, 390-395 (2006).

74 Kou, Y. C., Shao, L., Peng, H. H., Rosetta, R., del Gaudio, D., Wagner, A. F. et al. A recurrent intragenic genomic duplication, other novel mutations in NLRP7 and imprinting defects in recurrent biparental hydatidiform moles. Mol Hum Reprod. 14, 33-40 (2008).

75 Murdoch, S., Djuric, U., Mazhar, B., Seoud, M., Khan, R., Kuick, R. et al. Mutations in NALP7 cause recurrent hydatidiform moles and reproductive wastage in humans. Nat Genet. 38, 300-302 (2006).

76 Van den Veyver, I. B. \& Al-Hussaini, T. K. Biparental hydatidiform moles: a maternal effect mutation affecting imprinting in the offspring. Hum. Reprod. Update. 12, 233-242 (2006)

77 El-Maarri, O., Seoud, M., Coullin, P., Herbiniaux, U., Oldenburg, J., Rouleau, G. et al. Maternal alleles acquiring paternal methylation patterns in biparental complete hydatidiform moles. Hum Mol Genet. 12, 1405-1413 (2003).

78 Judson, H., Hayward, B. E., Sheridan, E. \& Bonthron, D. T. A global disorder of imprinting in the human female germ line. Nature. 416, 539-542 (2002).

79 Boissonnas, C. C., Abdalaoui, H. E., Haelewyn, V., Fauque, P., Dupont, J. M., Gut, I. et al. Specific epigenetic alterations of IGF2-H19 locus in spermatozoa from infertile men. Eur. J. Hum. Genet. : EJHG. 18, 73-80 (2010).

80 Hammoud, S. S., Purwar, J., Pflueger, C., Cairns, B. R. \& Carrell, D. T. Alterations in sperm DNA methylation patterns at imprinted loci in two classes of infertility. Fertil Steril. 94, 1728-1733 (2010).

81 Kobayashi, H., Sato, A., Otsu, E., Hiura, H., Tomatsu, C., Utsunomiya, T. et al. Aberrant DNA methylation of imprinted loci in sperm from oligospermic patients. Hum Mol Genet. 16, 2542-2551 (2007)

82 Marques, C. J., Carvalho, F., Sousa, M. \& Barros, A. Genomic imprinting in disruptive spermatogenesis. Lancet. 363, 1700-1702 (2004).

83 Marques, C. J., Costa, P., Vaz, B., Carvalho, F., Fernandes, S., Barros, A. et al. Abnormal methylation of imprinted genes in human sperm is associated with oligozoospermia. Mol Hum Reprod. 14, 67-74 (2008).

84 Marques, C. J., Francisco, T., Sousa, S., Carvalho, F., Barros, A. \& Sousa, M. Methylation defects of imprinted genes in human testicular spermatozoa. Fertil Steril. 94, 585-594 (2010).

85 Minor, A., Chow, V. \& Ma, S. Aberrant DNA methylation at imprinted genes in testicular sperm retrieved from men with obstructive azoospermia and undergoing vasectomy reversal. Reproduction. 141, 749-757 (2011).

86 Poplinski, A., Tuttelmann, F., Kanber, D., Horsthemke, B. \& Gromoll, J. Idiopathic male infertility is strongly associated with aberrant methylation of MEST and IGF2/ H19 ICR1. Int J Androl. 33, 642-649 (2010).

87 Kobayashi, H., Hiura, H., John, R. M., Sato, A., Otsu, E., Kobayashi, N. et al. DNA methylation errors at imprinted loci after assisted conception originate in the parental sperm. Eur. J. Hum. Genet. 17, 1582-1591 (2009).

88 El-Maarri, O., Kareta, M. S., Mikeska, T., Becker, T., Diaz-Lacava, A., Junen, J. et al. A systematic search for DNA methyltransferase polymorphisms reveals a rare DNMT3L variant associated with subtelomeric hypomethylation. Hum Mol Genet. 18, 17551768 (2009).

89 Market-Velker, B. A., Zhang, L., Magri, L. S., Bonvissuto, A. C. \& Mann, M. R. Dual effects of superovulation: loss of maternal and paternal imprinted methylation in a dose-dependent manner. Hum. Mol. Genet. 19, 36-51 (2010).

90 Sato, A., Otsu, E., Negishi, H., Utsunomiya, T. \& Arima, T. Aberrant DNA methylation of imprinted loci in superovulated oocytes. Hum. Reprod. 22, 26-35 (2007).

91 Cox, G. F., Burger, J., Lip, V., Mau, U. A., Sperling, K., Wu, B. L. et al. Intracytoplasmic sperm injection may increase the risk of imprinting defects. Am. J. Hum. Genet. 71, 162-164 (2002).

92 DeBaun, M. R., Niemitz, E. L. \& Feinberg, A. P. Association of in vitro fertilization with Beckwith-Wiedemann syndrome and epigenetic alterations of LIT1 and H19. Am. J. Hum. Genet. 72, 156-160 (2003).

93 Gicquel, C., Gaston, V., Mandelbaum, J., Siffroi, J. P., Flahault, A. \& Le Bouc, Y. In vitro fertilization may increase the risk of Beckwith-Wiedemann syndrome related to the abnormal imprinting of the KCN1OT gene. Am. J. Hum. Genet. 72, 1338-1341 (2003).

94 Halliday, J., Oke, K., Breheny, S., Algar, E. \& D, J. A. Beckwith-Wiedemann syndrome and IVF: a case-control study. Am. J. Hum. Genet. 75, 526-528 (2004).

95 Maher, E. R., Afnan, M. \& Barratt, C. L. Epigenetic risks related to assisted reproductive technologies: epigenetics, imprinting, ART and icebergs? Hum. Reprod. 18, 2508-2511 (2003).

96 Tierling, S., Souren, N. Y., Gries, J., Loporto, C., Groth, M., Lutsik, P. et al. Assisted reproductive technologies do not enhance the variability of DNA methylation imprints in human. J. Med. Genet. 47, 371-376 (2010). 
97 Bowdin, S., Allen, C., Kirby, G., Brueton, L., Afnan, M., Barratt, C. et al. A survey of assisted reproductive technology births and imprinting disorders. Hum Reprod. 22 3237-3240 (2007)

98 Savage, T., Peek, J., Hofman, P. L. \& Cutfield, W. S. Childhood outcomes of assisted reproductive technology. Hum Reprod. 26, 2392-2400 (2011).

99 Amor, D. J. \& Halliday, J. A review of known imprinting syndromes and their association with assisted reproduction technologies. Hum Reprod. 23, 2826-2834 (2008).

100 Stadtfeld, M., Apostolou, E., Akutsu, H., Fukuda, A., Follett, P., Natesan, S. et al. Aberrant silencing of imprinted genes on chromosome $12 \mathrm{qF} 1$ in mouse induced pluripotent stem cells. Nature. 465, 175-181 (2010).
101 Pick, M., Stelzer, Y., Bar-Nur, O., Mayshar, Y., Eden, A. \& Benvenisty, N. Clone- and gene-specific aberrations of parental imprinting in human induced pluripotent stem cells. Stem Cells. 27, 2686-2690 (2009).

102 Allegrucci, C., Thurston, A., Lucas, E. \& Young, L. Epigenetics and the germline. Reproduction. 129, 137-149 (2005).

103 Huntriss, J., Hinkins, M., Oliver, B., Harris, S. E., Beazley, J. C., Rutherford, A. J. et al. Expression of mRNAs for DNA methyltransferases and methyl-CpG-binding proteins in the human female germ line, preimplantation embryos, and embryonic stem cells. Mol. Reprod. Dev. 67, 323-336 (2004).

104 Hayashi, K., Ohta, H., Kurimoto, K., Aramaki, S. \& Saitou, M. Reconstitution of the mouse germ cell specification pathway in culture by pluripotent stem cells. Cell 146, 519-532 (2011). 